\title{
Effects of the Brazilian biodiesel certification in the relationship between the biodiesel industry and small-scale farmers
}

\author{
G. Marcossi ${ }^{1,2}$, D. Ortiz ${ }^{1} \&$ O. Moreno ${ }^{1}$ \\ ${ }^{I}$ Department of Economics and Social Science, \\ Polytechnic University of Valencia, Spain \\ ${ }^{2}$ Capes Foundation, Ministry of Education, Brazil
}

\begin{abstract}
The production of biodiesel in Brazil is encouraged by the government through the Fuel Stamp, a certification system linked to the National Plan for Production and Use of Biodiesel - PNPB - aimed at promoting economic and sustainable development. It focuses on social inclusion, also intending to reduce dependence on fossil fuels and emission of pollutants and diversify the energetic matrix through the use of different oil sources as raw material. Certification - and with it a number of tax benefits - are granted to industrial processors that are supplied with raw materials coming from small-scale farms. Thus, it facilitates the access of the family farms in this value chain. The objective of this work is to analyze the effects of this system of certification in the transactions between its main agents, farmers and processing industries. For this purpose, the work makes a revision of the studies that national public agencies have elaborated on regional cases and also scientific publications. Results show that this measure allowed the insertion of family farmers in the production chain and enabled the sustainable rural development. However, it presents gaps as the occurrence of failures in the fulfilment of contracts between family farmers and the industry. Moreover, in spite of being crop diversification, one of the objectives of the certification system, the preference of the industry for soy as raw material - because of technological reasons - is displacing traditional regional crops (for example palm and castor oil). Keywords: biodiesel production, small-scale farms, Brazilian agriculture, Social Fuel Seal, rural development.
\end{abstract}




\section{Introduction}

Biodiesel productive chain has a recent development in the world. In the case of Brazil, in spite of researches carried out over the last decades on this issue, it was only in 2004 that PNPB (National Program of Production and Use of Biodiesel) was officially launched by the government to consolidate the biodiesel market.

According to Milazzo et al. [1], in EU and the US sustainability and security of energy supply are the main concerns regarding biodiesel production, whereas in Brazil the socio-economic aspect is emphasized. The use of biodiesel as biocarburant energy indeed diminishes the dependence on fossil fuels and emissions of polluting gases. However, differently from the international tendency that puts focus on these environmental aims, biodiesel chain in Brazil divulges social inclusion as a fundamental pillar of its policy, in addition to the diversification of the energetic matrix using regional raw materials.

In order to encourage this social inclusion, a certification system was created the Social Fuel Seal (SFS), which is granted by the Ministério do Desenvolvimento Agrário (MDA) [2] to the biodiesel producers who obtain raw material from family farmers. By way of a contract, biodiesel processors are committed to providing technical assistance to farmers, and they receive as a benefit tax reduction (which varies according to the type of raw material and the region where it is obtained) and allowance to participate in biodiesel auctions organized by ANP (Agência Nacional de Petróleo), where biodiesel is bought. In most ANP auctions (80\%), the selling company needs to have the SFS. The formation of cooperatives among farmers is also stimulated to catalyse the transactions between them and industries, state Stattman and Mol [3].

An important issue regarding this chain in Brazil relates to natural advantages of this country, such as the territorial extension and favourable agro-climatic conditions for biomass production, according to Beneditti et al. [4]. However, despite these advantages Dos Santos et al. [5] warn that, if the government does not make the necessary interventions to diversify raw materials, the prevalence of soy, with higher yields and productive infrastructures controlled by large capital, will hinder the development of regional crops that may serve as raw material for biodiesel.

Within this context, the objective of this work is to analyse the effects of the Brazilian certification system in the transactions among its main agents, agricultural producers (and their cooperatives) versus processing industries. It is important to remark that the environmental aspects of biodiesel production exceed the scope of our study and will not be specifically tackled in this paper.

The remainder of this paper structures is as follows: in the following section, an overall picture of biodiesel production in Brazil is outlined. Section 3 tackles the main methodological aspects of this investigation. In Section 4, relationships among the main agents of the biodiesel chain are analysed in four case studies referred to different regions of Brazil. Discussion is carried out in Section 5, where positive and negative results will be assessed for each component of the chain: agriculture, manufacturing and distribution. Finally, we will present the conclusions of this study. 


\section{Background: current scenario of biodiesel in Brazil}

As Pereira et al. [6] state, there are numerous plants distributed throughout Brazil that process oil from different crops such as soy, palm, castor, babassu, sunflower and peanuts. All these oils are suitable for the production of renewable fuel - raw materials representing about $75 \%$ of biodiesel production costs in Brazil, according to Conab [7]. The choice of the raw material is influenced by the potential of the different oilseeds for each geographic region and climate, states Khalil [8]. Palm oil and babassu palm are more appropriate for north region and rapeseed, sunflower and cotton are more favourable in the south. However, the total production of soybean oil-based largely prevails in Brazil $(81.36 \%$ of total production), followed by the bovine fat $(13.36 \%)$ and cottonseed oil $(4.11 \%)$. The production of alternative crops is small and locally-based, as pointed out by Leonardi et al. [9].

Indeed, in spite of the efforts made to diversify the raw materials for biodiesel production, soybean large-scale monoculture production, with little demand for manpower (thanks to mechanization) and strong connection with commodity markets, is massively used as raw material despite its low oil content per hectare. Meanwhile, crops such as jatropha curcas, castor beans and palm, with a high oil content, do not experience any rapid expansion for biodiesel production. Soybean plantations already occupy $35 \%$ of the cultivated lands in Brazil, according to IBGE [10].

According to Conab [7], Brazil is the second largest soybean producer in the world, with a production of 81.3 million tons in the crop year 2012/2013. This production is led by the states of Mato Grosso, Paraná, Rio Grande do Sul and Goiás $(29 \%, 20 \%, 15 \%$ and $11 \%$ of the national production respectively), and is expanding to the eastern states of Maranhão, Tocantins, Piauí and Bahia.

As for the socio-economic aspects of biofuel production, Dos Santos et al. [5] recall that the PNPB establishes a linkage between an energy policy and a social policy, by certifying the biodiesel producers that buy $10-30 \%$ of their feedstock from family farmers.

According to Stattman and Mol [3] the PNPB allowed the introduction of biodiesel in the Brazilian energy matrix which established biodiesel mandates, initially B2 (2\% of biodiesel in diesel) to B5 (5\% of biodiesel in diesel) to be reached in July 2010. Under legal provision, the required percentage of biodiesel mixed with diesel passed from $5 \%$ to $6 \%$ from Jul $/ 2014$, and $6 \%$ to $7 \%$ from Nov/2014. However, justified by the public interest, the National Energy Policy Council may at any time reduce it to $6 \%$, states ANP [11].

Federal tax exemptions and incentives differentiate according to the utilized raw material, the size of the agricultural producer providing the raw material and the region of production. Steps are taken to stimulate biodiesel production and social inclusion mainly for family farmers in disadvantaged areas such as the semiarid Northeast and Amazon. Thus, the percentage family farmer feedstock necessary for the industry to obtain the SFS is $15 \%$ in Center-West and North, $30 \%$ in North-East and Semi-Arid and 30\% in South-East and South (year crop 2010/2011). 
According to ANP [11] there are 58 plants of biodiesel authorized by ANP to operate, corresponding to an authorized total capacity of $21,163.5 \mathrm{~m}^{3} /$ day (see Figure 1).

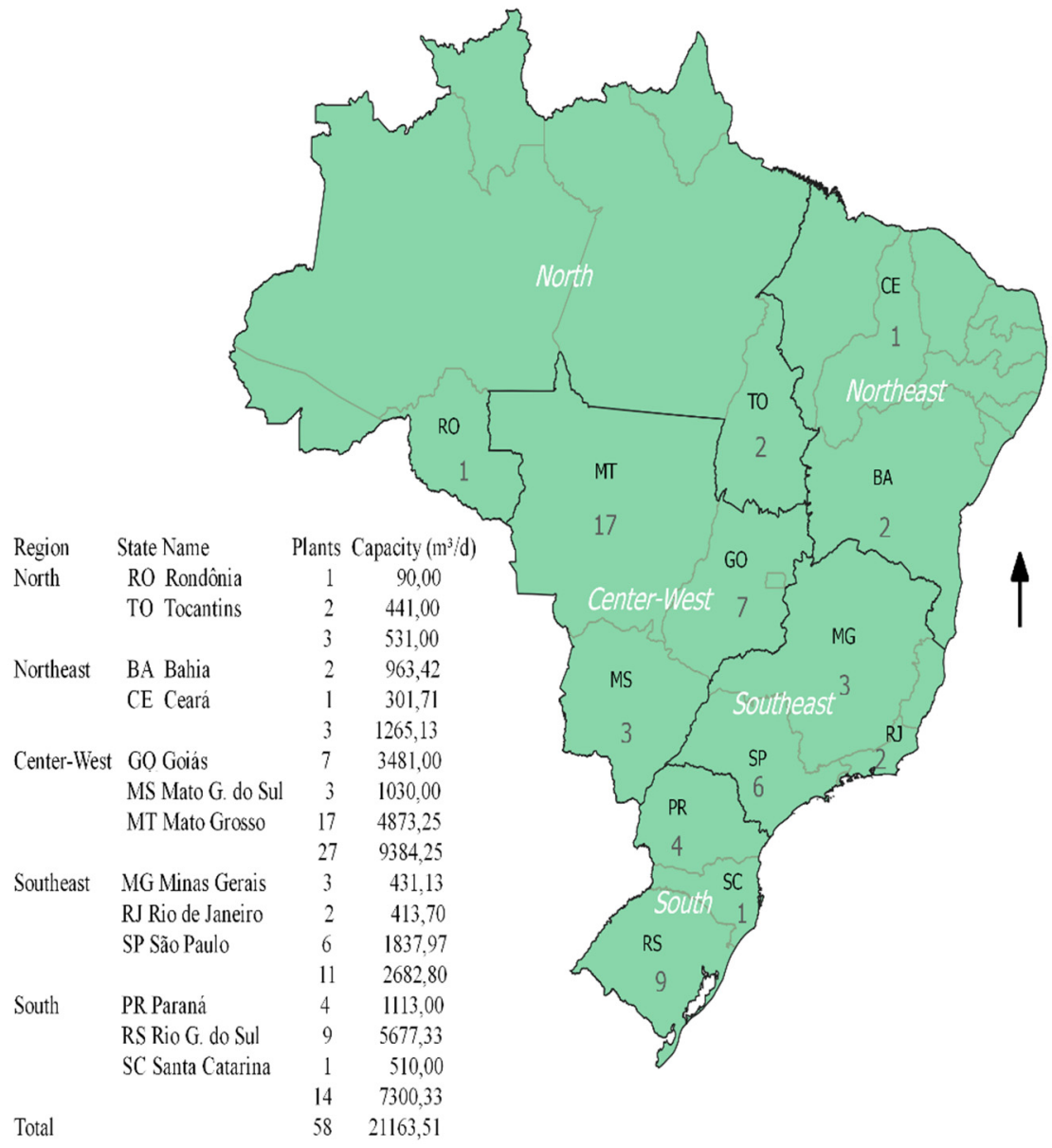

Figure 1: Biodiesel plants authorized $\left(\mathrm{m}^{3} / \mathrm{d}\right)$. Based on ANP (Dec/2014).

Finally, as regards to the economic impact of biodiesel production, it is important to note that it also stimulates the development of alcohol industry, consumed in the transesterification process for biofuel by the ethyl route, with the subsequent generation of employment and income, as highlighted by Pereira et al. [6].

\section{Methodology}

The information necessary for this work was obtained by way of an intensive review of the literature. Authors consulted national public agencies' reports and 
scientific publications that have elaborated on regional case studies, in order to determine the present situation of the investigated energetic sector.

Apart from scientific publications, consultations were made with competent organisms responsible for the biodiesel sector in Brazil such as MME, Ministry of Mines and Energy; EMBRAPA, Brazilian Farming and Livestock Research Agency; ANP, National Petroleum Agency; MDA, Ministry of Agriculture Development and CONAB, National Supply Company. International Symposiums that took place in Brazil were also used as reference, as well as journals with national impact.

Case studies will be analysed paying particular attention to the implications that the SFS is having for parties (small-farmers, cooperatives and industries), as well as the capacity of this certification to reduce uncertainty of transactions.

\section{Relationships among the main agents of the biodiesel chain in different regions of Brazil}

PNPB and the Social Fuel Seal have been widely known in several regions of Brazil and have had different effects in each case. For a better understanding, the analysis have been tackled separately for each region.

\subsection{The southern region, state of Rio Grande do Sul}

In the southern region, Dos Santos and Padula [12] analysed the way transactions occur in the biodiesel supply chain in Rio Grande do Sul. These authors state that before SFS was launched there was more opportunism in the relationships among actors, and family producers sometimes did not comply with their commitments with industries or cooperatives, commercialising the grain with another agent who offered a better price. This situation created uncertainties in the transactions and frequent changes of raw material suppliers.

With the implementation of SFS, industries are obliged to sign contracts assuring the grain value and technical assistance to family farmers. This fact made the transactions attached to the plants become more favourable to family producers, minimizing their intention to act in an opportunistic way. As a result, the variation of suppliers tend to diminish. The greater the confidence in the exchange relations among family farmers, the greater the frequency of transactions, what makes the chain structure more stable. The authors point out, however, that limitation of purchase in auctions with volumes and prices established by the government restrain the strategies of the industries and their profit possibilities.

Another empirical study by Silva et al. $[13,14]$, also focused in the southern region, analysed the impact of the SFS on the sustainable development from the industries' point of view. They found that a great motivation for these industries to insert in such market is the fact that PNPB guarantees the demand of biodiesel. The reason why industries choose SFS is a better participation in ANP auctions and the proximity to family farmers, since the Seal makes it possible to access to 
a bigger market share. The main suppliers of the industries are cooperatives that mediate the relationship with the family farmers.

As for sustainable development, this addresses the socio-economic and, to a lesser extent, the environmental impact of this policy. The increase in the profits for the industry, as well as the creation of jobs and income for the region (450 jobs in Cachoeira do Sul, a municipality located in Rio Grande do Sul, and connection with over 1000 farmers directly) are highlighted. It was also noted that the SFS allows the approximation and faithfulness of farmers previously set aside by the system. As one environmental issue, the authors mention the provision of technical assistance to orientate farmers towards the correct application of the chemical products, avoid waste and soil erosion - what also has a social lecture.

It is worth noting, as an important factor discussed in this study, that according to processors biodiesel production in Brazil does not greatly interfere in the production of food, even considering that frontiers of soya cultivation are expanding. Moreover, the by-product of biodiesel production, specifically bran at low price, is alleged to revert to more food since it can be used for animal feeding. Other positive factor underlined in this study is the stimulation of areas that generally would be unproductive during winter time.

A negative statement made by the industries is that the farmer who cultivates other crops hardly stops producing them to produce soya. In sum, the Seal brings the industries bureaucratic changes seen as a barrier but, in general, it is considered as an opportunity for their insertion in the market. The investigated industries reported that only because of the SFS they would have the intention to participate in the biodiesel production market. Before that time they did not visualize competitive advantage, what was only possible because of all the incentives of the policy (tax benefits and guaranteed participation in auctions).

\subsection{The south-eastern region, state of Minas Gerais}

The empirical analysis performed in the south-eastern region by Leite et al. [15] compares different types of farmers in two regions: the semi-arid areas and the more humid region of the Brazilian Southeast, both in the state of Minas Gerais. Each farming system shows a distinct decision-making process and requires specific solutions.

In the more humid region, medium-large scale farms, there is an annual rotation of soya followed by grass seed; this cultivation is made by means of intensive use of inputs (machinery, agrochemicals) and farms differed mainly in size (49.1 ha to $116.7 \mathrm{ha}$ ).

In the case of semi-arid areas, small-medium size ( 2.4 ha to 46.4 ha), diversity is the most prominent characteristic of this production system. Farms are less intensive, combine cultivation with cattle production on grassland (larger farm area) or use a part of the land to produce maize and beans for self-consumption (smaller farms), and show low market orientation.

In both research areas, yields of sunflower and castor bean are relatively low. The provision of soil nutrients helps farmers to increase oil production and economic profits. The contracts included farmers' technical assistance with seeds - inputs provided by biodiesel producers. 
In general, humid zone farms are more successful in obtaining information and credit and in delivering feedstock production, report Elbehri et al. [16]. In fact, farmers using soybean as raw material respond better to all terms of the policy of oil crop production and show higher gross margins than maize/beans farmers in semi-arid zones.

The potential of biodiesel crops for farmers in arid zones is lower than in humid zones, resulting in poor outcome in small-scale family farmers. These small-scale farmers were less affected by the biodiesel policy benefits, since the aggregate value associated with biodiesel oil crops was not sufficient to compete with traditional crops (i.e. beans). With fertilizer supply, sunflower crop could be a good alternative for these farmers.

Farmers and cooperatives indicate as an alternative to improve the viability of biodiesel production crushing the oil feedstock locally, through the deployment of small-scale oil extraction units, what could reduce current transportation distance by $75 \%$.

\subsection{The north-eastern region, state of Bahia}

According to Stattman and Mol [3], the government noted complications with the implementation of the PNPB in this area due to the fact that biodiesel companies had little experience with technical assistance for family farmers.

Family farmers had small land areas, and they were only partly available for biodiesel feedstock production. Small producers also had little experience with biodiesel crops and seed provisions were not always appropriate or timely provided, resulting in low harvests, state Kilham et al. [17]. Contracts between family farmers and biodiesel industry were often ignored by farmers because they do not have business experience and preferred to produce other crops, what favoured local traders. In addition, a lack of commitment by industry as regards to payments and seed delivery is reported by Watanabe et al. [18]. Problems such as high logistical and transaction costs were recurrent.

From 2009, industries were allowed to buy biodiesel feedstock from agricultural cooperatives, and still receive the desired SFS if the cooperative has the legal permission emitted by the MDA. The number of cooperatives and farmers involved in biodiesel production have increased ever since because of the new market opportunities and the provision of technical assistance and seeds for farmers. Financial support for technical assistance and biodiesel contracts allowed the professionalization of cooperatives and more participation in the PNPB. As for the benefits for individual farmers, these authors mention the assistance for irrigation and for crops adapted to the agro-ecological conditions of the region. A local seed bank was also developed to improve productivity.

Cooperatives agree that medium-sized family farmers are better benefitted from the technical assistance and better adapt farming practices, because they have greater capacity to use new knowledge and change old production practices. The smallest farmers in remote areas produce what is essential to their subsistence and have less ability for structural changes, thus they benefit less from this policy, add Watanabe et al. [18]. In addition, they do not always understand the cooperative system. Distance and poor infrastructure complicate agricultural assistance in 
remote areas. In general, these farmers choose not to join the PNPB or are not interested in becoming members of cooperatives. Some cooperatives report that farmers are not fully aware of the potential benefits of the policy for them.

There is uncertainty for cooperatives due to a significant dependence on the SFS for their establishment in the biodiesel market. Many cooperatives identify, as negative cases, industries that only use soy for biodiesel production and sell the other vegetable oils (castor and palm) to other industries, because they get higher market value for uses different to biodiesel production, as reported by César and Batalha [19]. In addition, some farmers do not want to stop negotiating with other potential buyers of their raw materials, breaking the contract assumed by SFS.

In sum, the PNPB states to have succeeded in stimulating agricultural modernization and innovation and thus the social inclusion of family farmers, but not all of them are equally benefitted from this policy. Cooperatives operate as instruments for the government to reach small farmers thus channeling technical advice, seeds, infrastructure and credit facilities to members. They created horizontal links between farmers and a vertical link between farmers and state/business organizations network, conclude Stattman and Mol [3].

\subsection{The northern region, Amazon}

In Brazil, palm crop is normally cultivated in the Amazon region, due to its good climate conditions for high oil palm productivity. Palm has a higher productivity than other oilseeds (3-6 tons of oil/ha by year), as well as more energetically efficient than other biodiesels and fossil fuels. According to César et al. [20] palm oil is not yet an important part of the biodiesel chain; in 2012, palm represented only $0.32 \%$ of this business. However, support policies such as easy credit and tax incentives reduce the cost of production and enable the competitiveness of this cultivation and regionalization of biodiesel production.

The intensive use of manpower, year-round production and good business opportunities are positive aspects of oil palm cultivation by family farmers. Moreover, this oilseed can be cultivated together with subsistence farming and intercropping with short cycle crops such as beans and corn. However, the production by family farmers is still experimental. Industries are only beginning to identify the family farmers in the northern region to participate in the production of palm. The strategy is to set processing plants in new nearby areas.

The SFS were signed with a small number of farmers to detect and correct failures before implementing it on a larger scale. Technical assistance is constant, which allows a better connection between industries and the small producers. According to these researchers, although there are groups of rural workers in the North of the country, cooperatives are still beginning to operate in this region.

As negative factors, the authors point out that the transportation infrastructure in palm cultivation regions is precarious. Industries often have to build and maintain roads. Difficulties related to register the family farmers interested in participating in PNPB are also reported, due to difficulties in accessing the regions where their properties are located.

The price of oil palm is currently high, what is considered another barrier in spite of its higher quality. These authors conclude that it is possible to expand its 
production to large scales if there is private and public participation to supply the food industry and the biodiesel chain.

For the time being, biodiesel production is less profitable than food industry considering oil palm, but biodiesel chain can also promote fuel supply in many isolated places of the northern region. According to these researchers, the use of oil palm appears to be a viable medium-term possibility, contributing to biodiesel chain and social inclusion of family farmers. The SFS quota for the North of the country is encouraging to engage processing industries.

\section{Discussion}

Table 1 summarises the main implications that, according to the analysed studies, the SFS has for participants (small-scale farmers, cooperatives and industries).

Table 1: Implications of SFS and biodiesel expansion.

\begin{tabular}{|c|c|}
\hline Actor & \\
\hline $\begin{array}{l}\text { Small-scale } \\
\text { farmers }\end{array}$ & $\begin{array}{l}\text { - SFS is making possible the access to this chain for many small- } \\
\text { farmers. } \\
\text { - It is promoting farm diversification. } \\
\text { - Farmers receive training and in some cases inputs (e.g. seeds) } \\
\text { provided by industries. } \\
\text { - Technical assistance orientates the producer towards the correct } \\
\text { application of the chemical products avoiding waste and soil } \\
\text { erosion. } \\
\text { - Some participants face difficulties to stock their production in their } \\
\text { small holdings. } \\
\text { - Little experience with energy crops and difficulties to access } \\
\text { appropriate seeds, resulting in low yields. } \\
\text { - Subsistence farmers can hardly adopt the necessary changes to } \\
\text { produce energy crops. }\end{array}$ \\
\hline Cooperatives & $\begin{array}{l}\text { - Strengthening and professionalization of cooperatives. } \\
\text { - Cooperatives are investing in new facilities and equipment because } \\
\text { of their relationships with industries. } \\
\text { - However, investments make cooperatives very dependent on the } \\
\text { maintenance of the SFS. }\end{array}$ \\
\hline Industries & $\begin{array}{l}\text { - Easier access to public credit and tax incentives. } \\
\text { - Better conditions to participate in ANP auctions. However, they are } \\
\text { restricted to public auctions and cannot resort to other potential } \\
\text { buyers. } \\
\text { - Contracts do not reduce industries' uncertainty, since sometimes } \\
\text { farmers adopt opportunistic behaviour (in spite of the contracts, } \\
\text { they sell to other buyers if they are offered a better price). This } \\
\text { leads industries to look for new suppliers continually. The } \\
\text { participation and mediation of cooperatives is reducing uncertainty. } \\
\text { - There are several logistic and accessibility problems to access to } \\
\text { farmers production. In some cases industries have to construct } \\
\text { roads and access to get raw material from some areas. }\end{array}$ \\
\hline
\end{tabular}

Source: Authors' elaboration 
Besides the implications that SFS is having for participant farmers, the analysed studies also show that the system is side-lining other small farmers. In some cases, they are farmers located in remote areas with poor infrastructures, so that transportation costs are very high. In other cases, some small-farmers are reluctant to introduce some productive and managerial changes, particularly when they produce for self-consumption. Moreover, there are also farmers who prefer not to join cooperatives - which are channelling raw material from farmers to industries, so they keep out of this value chain.

From the point of view of regional crop diversification, authors point out that biodiesel production would not interfere with regional food production, which would prevent food insecurity implications. Nevertheless, the federal government's aim to promote energy crops diversity is not being realized due to infrastructure constraints and incipient technological development.

\section{Conclusions}

The consolidation of the biodiesel sector is still in process and depends on macro factors like government policies and micro questions like the input availability and production costs for each region and raw material. In spite of the PNPB and the SFS, important regional disparities persist regarding its performance (consolidation of cooperative structures, technological developments, diversity of raw material). Moreover, although SFS has allowed many small-farmers and cooperatives to participate and profit from this value chain, some uncertainties remain, particularly regarding the opportunistic behaviour of some farmers or the dependence of cooperatives on stable industries' demand.

On the other hand, according to WEF [21], government may impose additional costs and slow down the development of biodiesel sector due to excessive bureaucracy, overregulation and inability to provide appropriated services for the sector.

Issues related to sustainable development, with regard to the environment, should be analyzed more deeply, in order to achieve more tangible results.

\section{References}

[1] Milazzo, M.F., Spina, F., Cavallaro, S., Bart, J.C.J., Sustainable soy biodiesel. Renewable and Sustainable Energy Reviews, 27, pp. 806-852, 2013.

[2] Ministério do Desenvolvimento Agrário (MDA); www.mda.gov.br.

[3] Stattman, S.L. \& Mol, A.P.J., Social sustainability of Brazilian biodiesel: The role of agricultural cooperatives. Geoforum, 54, pp. 282-294, 2014.

[4] Benedetti, O., Plá, J.A., Rathmann, R., Padula, A.D., Uma proposta de modelo para avaliar a viabilidade do biodiesel no Brasil, Teoria e Evidência Econômica, v. 14, pp. 81-107, 2006. www.Upf.Tche.Br/Cepeac/Download/ Rev_Esp_2006_Art4.Pdf.

[5] Dos Santos, S.F., Borschiver, S., Souza, V., Mapping sustainable structural dimensions for managing the Brazilian biodiesel supply chain. Journal of Technology Management \& Innovation. 9, Issue I, pp. 27-43, 2014. 
[6] Pereira, M.G., Camacho, C.F., Freitas, M.A.V., Da Silva, N.F., The renewable energy market in Brazil: current status and potential. Renewable and Sustainable Energy Reviews, 16, pp. 3786-3802, 2012.

[7] Companhia Nacional de Abastecimento (Conab); www.conab.gov.br.

[8] Khalil, C.N., As tecnologias de produção do biodiesel. O Futuro da Indústria: Biodiesel, ed. MDIC-STI/IEL, Brasília, Brazil, 14, pp. 83-90, 2006.

[9] Leonardi A., Borges J.A., Freitas J.B., Zonin V.J., Scarton L.M., Advantages of the social stamp for the biodiesel producer companies: the BSBIOS and Oleoplan cases. Proc. Of the VII Int PENSA Conf., São Paulo, SP, Brazil; pp. 1-11, 2009.

[10] Instituto Brasileiro de Geografia e Estatística (IBGE). Municipal agricultural production; 2009. www.sidra.ibge.gov.br.

[11] Agência Nacional do Petróleo, Gás Natural e Biocombustíveis, ANP; www.anp.gov.br.

[12] Dos Santos M.S. \& Padula A.D., A transação como fator estruturante da cadeia de suprimento do biodiesel no Rio Grande do Sul. Revista Eletrônica de Ciência Administrativa (RECADM), 11(2), pp. 178-192, 2012.

[13] Silva A.H., Araújo R, Moura G.L., Cunha D.E., Avaliação do impacto do Selo Combustível Social na indústria de biodiesel do Rio Grande Do Sul. International Symposium of Project Management, S2IS International Symposium of Innovation and Sustainability, São Paulo, SP, Brazil, 2013.

[14] Silva A.H., Dos Santos R.A., Moura G.L, Parnoff L., O Selo Combustível Social e o desenvolvimento sustentável: A ótica da empresa gaúcha. International Symposium of Project Management, S2IS International Symposium of Innovation and Sustainability, São Paulo, SP, Brazil, 2013.

[15] Leite J.G.D.B, Silva J.V., Ittersum M.K.V., Integrated assessment of biodiesel policies aimed at family farms in Brazil. Agricultural Systems, 131, pp. 64-76, 2014.

[16] Elbehri, A., Segerstedt, A., Liu, P., Biofuels and the sustainability challenge: A global assessment of sustainability issues, trends and policies for biofuels and related feedstocks. FAO, Rome, 2013.

[17] Kilham, S., Camargo, C., Willetts, J., Biodiesel: farmer's perspectives from Bahia Brazil. Prepared for ETC. Foundation by the Institute for Sustainable Futures. University of Technology, Sydney, 2010.

[18] Watanabe, K., Bijman, J., Slingerland, M.A., Institutional arrangements in the emerging biodiesel industry: case studies from Minas Gerais, Brazil. Energy Policy, 40, pp. 381-389, 2012.

[19] César, A.S., Batalha, M.O., Biodiesel production from castor oil in Brazil: a difficult reality. Energy Policy, 38, pp. 4031-4039, 2010.

[20] César A.S., Batalha M.O., Zopelari A.L.M.S., Oil palm biodiesel: Brazil's main challenges. Energy, 60, pp. 485-491, 2013.

[21] WEF. The Global Competitiveness Report 2012-2013. ed. K. Schwab, p. 545. Geneva: World Economic Forum, 2012. 